\title{
Research on Barcode Application Technology for Aircraft Development
}

\section{Cycle}

\author{
YongGuo Zhu ${ }^{1,2, a *}$, JunJie $\mathrm{Li}^{2, \mathrm{~b}}$, Likang Song ${ }^{1, \mathrm{c}}$, JianHua $\mathrm{Yu}^{1, \mathrm{~d}}$ \\ ${ }^{1}$ Jiangxi Hongdu Aviation Industry Group Limited liability Company, Xinxiqiao Road, Qingyun \\ District, Nanchang City, Jiangxi Prov. China 330024; ${ }^{2}$ School of Aviation Manufacturing \\ Engineering, Nanchang Hangkong University, No.696, Fenghenan Road, Nanchang City, Jiangxi \\ prov. China 330063 \\ azhuyongguo_2003@163.com, 'quiuqiu08080333@163.com \\ 'slk@hongdu.com.cn, ${ }^{\mathrm{d}}$ wtyjh83@sina.com
}

Key words: aircraft; barcode application; manufacturing information; single aircraft; quality files Abstract. As an information collection and automatic identification technology, barcode can be used to collect information accurately and quickly. So the barcode technology is introduced into the whole cycle of aircraft manufacturing. This paper puts forward the oriented method of the aircraft development cycle of barcode application and gives the system implementation scheme. The whole development cycle of aircraft analyzes the barcode applications, coupling of logistics and information flow, sharing manufacturing information, establishing the single aircraft sorties quality files. The system will effectively enhance the level of aircraft development and have positive significance for building digital factory.

\section{Introduction}

As a technology of information collection and automatic identification, barcode technology has the advantages of fast input speed, high reliability, high information capacity and so on [1] [2], which can solve the problems of slow and the problems of the prone error of the traditional marking method. The barcode technology is easy to be used in various information systems, and is widely used in the fields of automobile, ship, aircraft and so on [3] [4].

Aircraft development cycle process requires the higher characteristics of material variety, small batch, many flow, processing and assembly process complex, large amount of information, quality control requirements, so the aircraft manufacturing enterprises using barcode technology to solve the aircraft development cycle of material flow, process information, quality control information. Although the aircraft manufacturing enterprises adopting the barcode technology, but also need to improve the application of the barcode. Li Baolong and others proposed the application of barcode technology in the aviation manufacturing process of material management, to solve the problem of the application of barcode in the core of attachment management, but the application of barcode in the process of aircraft development cycle is obviously insufficient [5]. 
Jiang Meilian and others proposed the application of barcode technology in supply chain management to solve the information needs of the raw material supply, production, storage, distribution and other information needs in the management, but not very well to solve the problem of information sharing in the process of aircraft manufacturing [6]. Zhang Feng proposed the application of two-dimensional barcode in the management system of aircraft spare parts, solved the problems of the management of the production and sales of aircraft spare parts and inventory management, but not very well to solve the problems in the development of processing and assembling in aircraft development cycle of barcode applications [7].

In order to solve the problems of the application of the barcode in the aircraft development cycle of procurement, inventory, distribution, processing, assembly, quality control. The method of barcode application is put forward and the architecture of barcode management system is established. The system implementation scheme is given to improve the level of information management of aircraft manufacturing industry.

\section{Barcode Technology Application of Whole Development Cycle of Aircraft}

The whole development cycle management use the barcode technology, recording the production process of the aircraft parts, monitoring the quality of each management. At the same time, the production data can be statistical and searched. The production data provides the basis for the production scheduling, arranging the scheduling production and so on. The whole development cycle management includes: production plan, procurement management, inventory management, distribution management, processing management, assembling management, quality management. Scientific research and production department orders production plan. Production plan includes the material requirements plan and delivery plan. Material requirement plan includes a certain type aircraft sorties, batch, stage, daily production material requirements. Distribution plan includes certain day, certain location, and certain workshop of the distribution task. Procurement management includes procurement plan, suppliers, procurement, inspection, warehouse, returned purchase. Inventory management includes inbound/outbound storage, arranging positions, inventory. Distribution management includes blanking, classification, shipment, distribution. Processing management includes material processing, parts processing, tools processing, on-site progress collection. Assembling management includes the parts assembly, on-site progress collection. Quality management includes the material quality inspection, blanking quality inspection, process quality inspection, assembly quality inspection.

The production plan of barcode applications includes the required material barcode. The procurement management of the barcode applications includes procurement barcode, material barcode, barcode quality and return barcode. The application of the barcode for the inventory management includes the inventory barcode. The application of the barcode for the distribution management includes the distribution barcode, the blanking code, the quality barcode. The 
application of the barcode in the management of the machine includes the processing instruction and the quality barcode. The application of the barcode for assembly management includes assembly instruction and quality barcode.

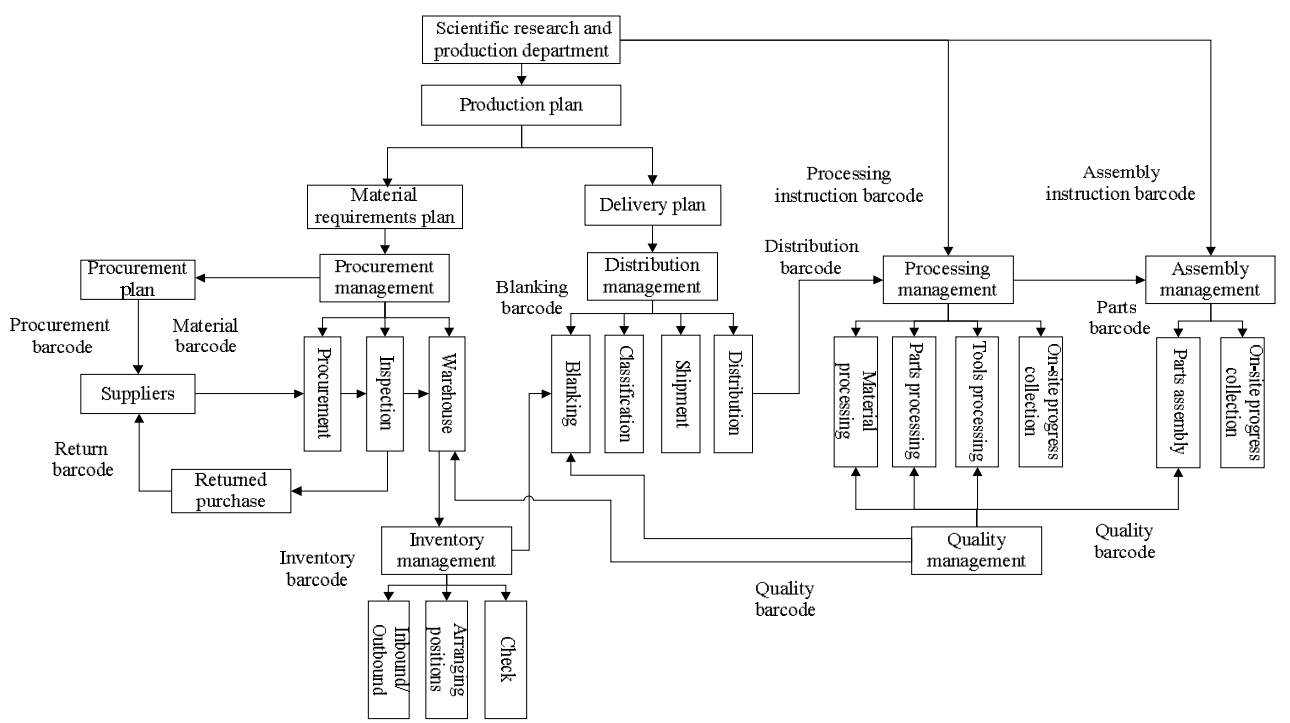

Fig. 1 Application of the whole development cycle management barcode

Coupling of Logistics and Information Flow. Aircraft development involves many kinds of materials. In order to ensure the accurate arrival of the materials to each the management department by coupling of logistics and information flow coupling, which can facilitate aided manufacturing. Logistics includes from material to inventory management, distribution management to the process management, and then to the assembly management. The flow of information includes the list of material requisition, the list of distribution, the list of processing tasks, the list of transferring documents and the list of assembly tasks. The list of material requisition includes material barcode, quantity, specifications and other information. The list of distribution includes the distribution workshop, location quantity and other information. The list of processing tasks includes the processing instruction barcode, the labor card and other information. The list of transferring documents includes the transfer of barcode and the information of the workshop. The list of assembly task includes information such as assembly instruction barcode, tooling tools, etc. Figure 2 shows the coupling of logistics and information flow. 


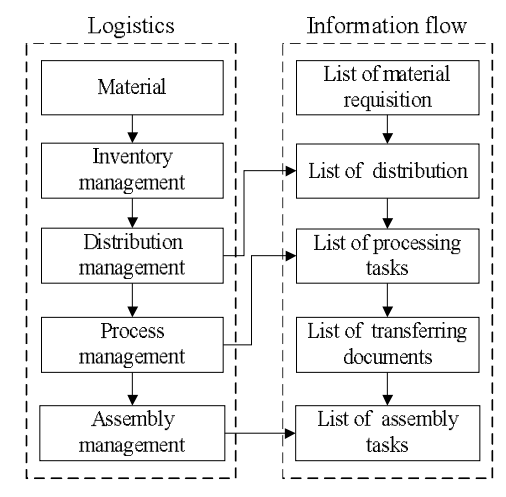

Fig. 2 Coupling of logistics and information flow

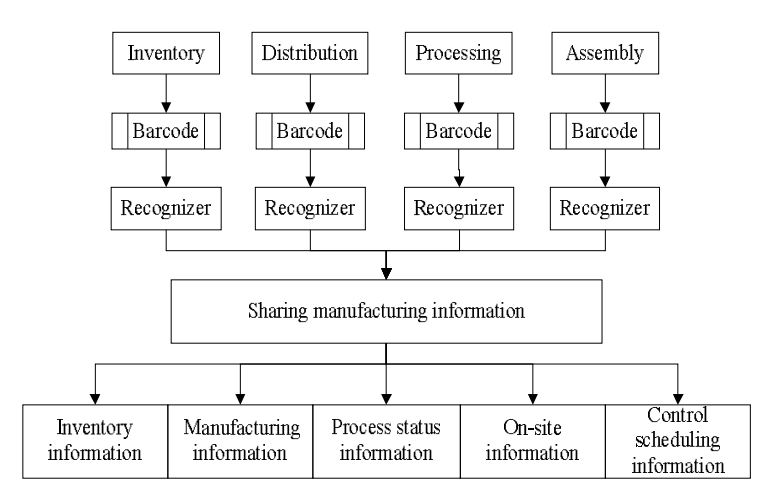

Fig. 3 Sharing manufacturing information

Sharing Manufacturing Information. The recognizers read the barcode of the inventory, distribution, processing, assembly management and share the reading of information. Inventory, distribution, processing and assembling can be real-time monitoring. So the managers can timely solve the problems such as quality and schedule for management and control. Sharing manufacturing information includes inventory information, manufacturing information, process status information, on-site information and control scheduling information. Inventory information includes material, location, quantity, maintenance and other information. Manufacturing information includes the material information, the batch number, the current location number, the flow direction and the notes. Process status information includes the material information, batch number, the current processing station number and the current assembly station number. The problem information in the field includes the information of material and equipment. Control scheduling information includes comprehensive distribution, processing and assembly status, on-site problem processing information. Figure 3 shows sharing manufacturing information.

Single Aircraft Sorties Quality Files. The aircraft development cycle barcode management use barcode by aircraft development cycle of barcode management system. The system collects, summarizes and classifys the barcode information of the whole aircraft development cycle. Then the system establishes the single aircraft sorties quality files to track and trace the quality of aircraft parts by reading of barcode information. Single aircraft sorties quality files include: material information, processing information, assembly information, changing information, information quality and exception information. Material information includes material and its auxiliary parts manufacturers, brand, name, batch, certificate, date of production and other information. Processing information includes raw materials, workblank, blanking, processing procedures and other information. Assembly information includes assembly parts list, assembly process, etc. Changing information includes design changes, process changes, etc. Quality information includes the material into the factory inspection, the blanking inspection, the processing inspection, the equipment inspection and so on information. Exception information includes information such as non-qualified products and quality issues. Figure 4 shows the single aircraft sorties quality files. 


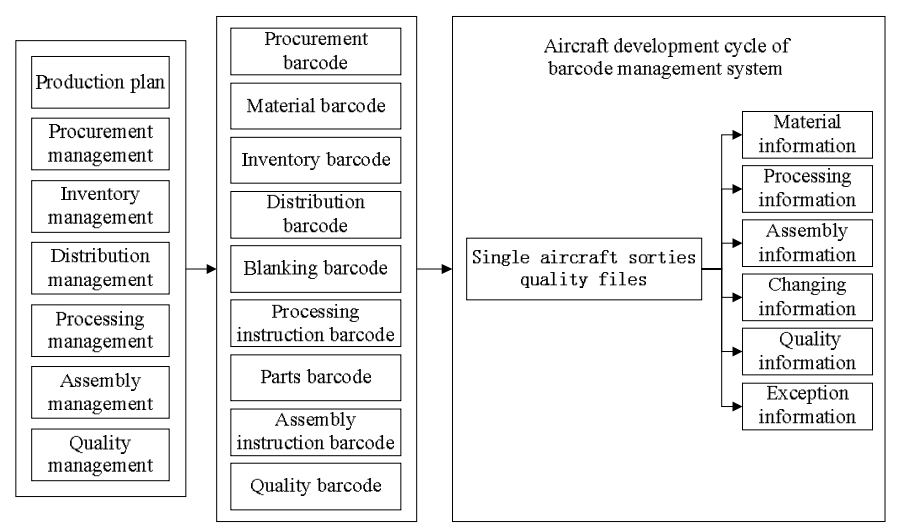

Fig. 4 Single aircraft sorties quality files

\section{Architecture of the Aircraft Development Cycle Barcode Management System}

Aircraft development cycle of barcode management system on the management of the application of barcode, the department can track the production of aircraft parts and use the logistics and information flow coupled aided manufacturing. In the aircraft manufacturing process, the system collects barcode and shares information what it gets in real-time acquisition of the barcode. The way is convenient for the production data that can be statistically and be checked. The production data provides the basis for the production scheduling, arranging the scheduling production and so on. At the same time, to set up single aircraft sortie quality files, convenient for the aircraft parts quality traceability. Aircraft development cycle of barcode management system architecture includes the several points: the whole development cycle management, logistics and information flow coupling, manufacturing information sharing and single aircraft sorties quality files. Figure 5 shows the structure of the aircraft development cycle barcode management system.

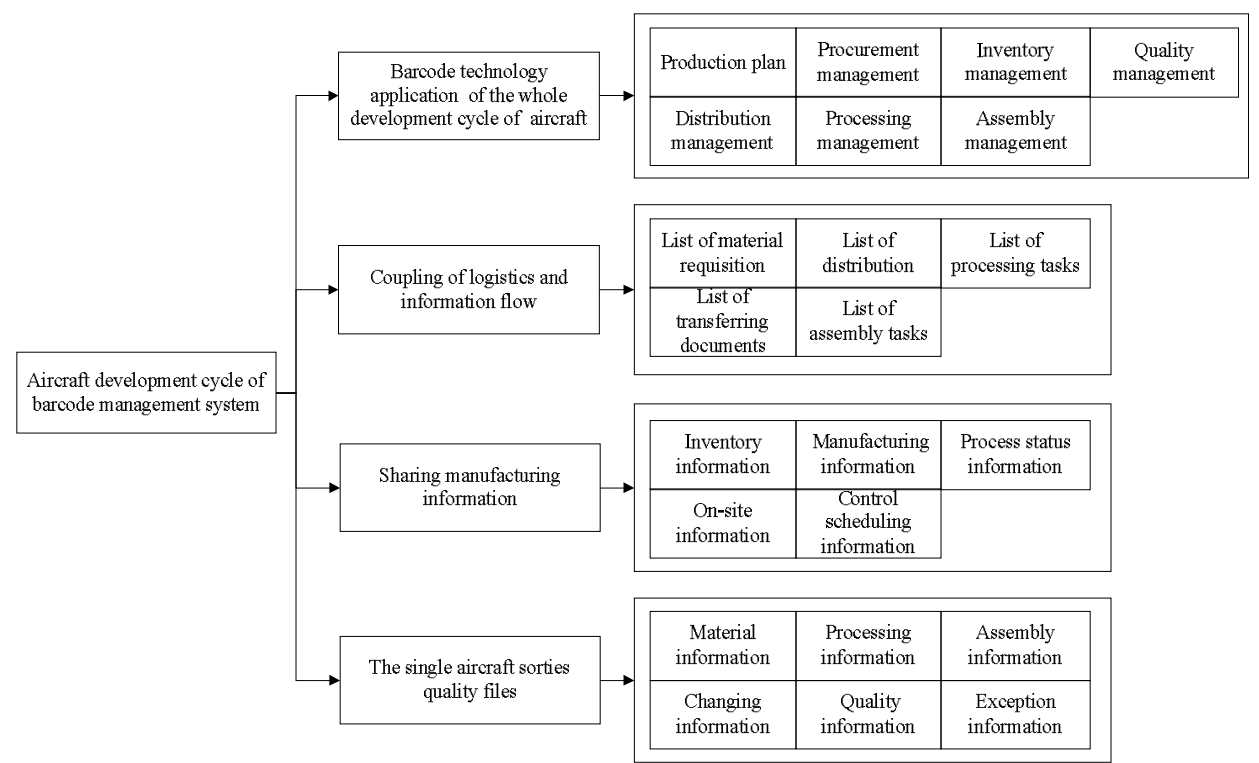

Fig. 5 Structure of the aircraft development cycle barcode management system

\section{Project of System Implementation}

Aircraft development cycle barcode management system runs the local area network, which is based on $\mathrm{C} / \mathrm{S}$ (Client/Server) and B/S (Browser/Server) with the combination of hybrid model 
of development. Through the C/S mode client, the system can collect the barcode and access to the server database. The manufacturing information of barcode are displayed on the client. Through the development of the B/S model of the aircraft development cycle barcode management system. The information of barcode will be collected, summarized and classified. This information is in the form of web pages to the procurement staff, management personnel, technical personnel, etc. To facilitate their rapid access to the information they need. For B/S and $\mathrm{C} / \mathrm{S}$ hybrid mode, the local fixed that data query is flexible use a small range of $\mathrm{C} / \mathrm{S}$ mode and the place that has the web of the function use the way of B/S mode. Figure 6 shows the hybrid model based on $\mathrm{C} / \mathrm{S}$ and $\mathrm{B} / \mathrm{S}$.

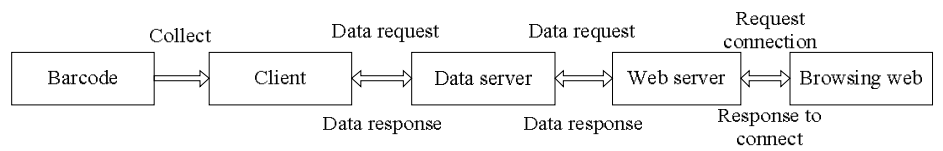

Fig. 6 Hybrid model based on $\mathrm{C} / \mathrm{S}$ and $\mathrm{B} / \mathrm{S}$

Using the hybrid model based on $\mathrm{B} / \mathrm{S}$ and $\mathrm{C} / \mathrm{S}$, the system can be developed. It not only can improve the system's development efficiency, but also can enhance the security, expansibility and maintenance of the system.

(1) System development environment: the development platform of Eclipse; the development language of Java; the database of Oracle.

(2) System operating environment: the client for barcode acquisition handset Casio DT-X10; server operating system for Microsoft Windows Server 2008; web services for Apache Tomcat 6.0; the Oracle database system; browse the web for Windows XP/Windows 7; above for IE5.0 browser.

\section{Conclusions}

Some aviation aircraft manufacturing enterprise after using the system, the development cycle is shortened and the production efficiency is improved. The stock share is effectively reduced. The cost of logistics is reduced. The economic benefit of enterprises is improved. Researching on the method of the aircraft development cycle barcode management system is significant to build a digital and the flexible aircraft of intelligent assembly workshop and improve the overall level of aviation manufacturing industry.

\section{References}

[1] Ma Fang, Yan Yingjian. Barcode Technology in Application of Manufacturing Industry [J]. Modular Machine Tool \& Automatic Manufacturing Technique, 2001 (5): $46-48$

[2] Dai Yunweng, Li Yang. Design and Implementation of Barcode Mangagement Information System [J]. Electrical Engineering, 2012(154): 1200-1207

[3] Chen Baoguo, Xu Jianguo. Barcode Technology in Application of Management Information System [J]. Management Information System, 2009 (7): 93-95

[4] Ou Yangping, Sun Wenwen. Research on Application of Barcode Technology in Aircraft 
Manufacturing [J]. Trainer, 2013 (9): 37-41

[5] Li Baolong, Zhao Yi, Tang Yanhong. Application of Barcode Technology in Aviation Manufacturing Process Material Management [J]. Computer and Modernization, 2008 (5): 121-123

[6] Jiang Meilian, Lin Zhaohua, Deng Yaoguo. Application of Barcode Technology in Supply Chain Management [J]. Light Industry Machinery, 2008.26 (2): 116-118

[7] Zhang Feng. Research of Aircraft Spare Part Management System Scheme Based on Two-dimensional Barcode [J]. Electronic Design Engineering,2010.18(8):93-96 